\title{
Selective Serotonin Reuptake Inhibitor Use During Pregnancy and Major Malformations: The Importance of Serotonin for Embryonic Development and the Effect of Serotonin Inhibition on the Occurrence of Malformations
}

\author{
Anick Bérard, PhD, Michael Levin, $\mathrm{PhD}^{2}$, Thomas Sadler, $\mathrm{PhD}^{3}$, and David Healy, $\mathrm{MD}^{4}$
}

\begin{abstract}
Bioelectric signaling is transduced by neurotransmitter pathways in many cell types. One of the key mediators of bioelectric control mechanisms is serotonin, and its transporter SERT, which is targeted by a broad class of blocker drugs (selective serotonin reuptake inhibitors [SSRIs]). Studies showing an increased risk of multiple malformations associated with gestational use of SSRI have been accumulating but debate remains on whether SSRI as a class has the potential to generate these malformations. This review highlights the importance of serotonin for embryonic development; the effect of serotonin inhibition during early pregnancy on the occurrence of multiple diverse malformations that have been shown to occur in human pregnancies; that the risks outweigh the benefits of SSRI use during gestation in populations of mild to moderately depressed pregnant women, which encompass the majority of pregnant depressed women; and that the malformations seen in human pregnancies constitute a pattern of malformations consistent with the known mechanisms of action of SSRIs. We present at least three mechanisms by which SSRI can affect development. These studies highlight the relevance of basic bioelectric and neurotransmitter mechanism for biomedicine.
\end{abstract}

Keywords: maternal depression, congenital malformations, SERT, ion channel, asymmetry, laterality

\section{Introduction}

$\mathbf{T}$ ERATOGENS ARE FACTORS that alter or interfere with embryonic development resulting in malformations, death, growth retardation, or functional deficits in the embryo or fetus. ${ }^{1}$ That drugs can act as human teratogens has been accepted by the medical and scientific communities for $>50$ years. Agents such as thalidomide, retinoic acid, and antiepileptics, to name a few, are compounds that are teratogens as demonstrated by epidemiological methods, principles, and criteria. Recent epidemiological research has shown that selective serotonin reuptake inhibitors (SSRIs), the most commonly used class of antidepressants, by their common mechanism that inhibits reuptake of serotonin or 5-hydroxytryptamine (5-HT) by the serotonin transporter (SERT or 5-HTT), increase the risk of spontaneous abortions, major congenital malformations, intrauterine growth retardation, prematurity, and cognitive delay. ${ }^{2-20}$
In addition to the fact that data are accumulating that demonstrate a risk of major congenital malformations associated with SSRI use during gestation, the efficacy of these drugs for the treatment of depression has been questioned. For example, due to increased maternal metabolism during pregnancy, ${ }^{21}$ SSRI drug dosage should be increased to maintain the same prepregnancy effectiveness. ${ }^{22}$ However, evidence shows that the majority of women maintain or decrease their SSRI dosage once their pregnancy is diagnosed. ${ }^{21}$ Therefore, if there were benefits to SSRI use before pregnancy, this is no longer the case during pregnancy. Furthermore, the majority of depressed women are moderately depressed, ${ }^{23}$ and the risk to the unborn child of using SSRIs outweights the benefits in this population, given that exercise or psychotherapy is now known to be effective alternatives to taking the drugs. ${ }^{23}$

According to the United States Food and Drug Administration (FDA)'s Established Pharmacologic Class, ${ }^{24}$ SSRIs are an established pharmacological class because they all

${ }^{1}$ Faculty of Pharmacy, University of Montreal; Research Center, CHU Sainte-Justine, Montreal, Quebec, Canada.

${ }^{2}$ Allen Discovery Center at Tufts University, Department of Biology, Medford, Massachusetts.

${ }^{3}$ Department of Pediatrics, School of Medicine, University of Utah, Salt Lake City, Utah.

${ }^{4}$ Department of Psychiatry, Hergest Unit, Bangor, United Kingdom. 
have the same mechanism of action, which is to inhibit 5-HT reuptake by SERT, thereby increasing extracellular concentrations of the neurotransmitter. By these criteria, the drugs sertraline, paroxetine, citalopram, escitalopram, and fluoxetine belong to this established pharmacological class. ${ }^{24}$ In fact, all drugs with potent serotonin reuptake inhibiting effects constitute a class-this includes SSRIs but also venlafaxine, desvenlafaxine, duloxetine, and clomipramine.

This review presents the available evidence concerning the effects of SSRIs on the fetus during pregnancy as well as the role of 5-HT in normal embryonic development. We posit at least three types of mechanisms by which SSRIs can affect development (Fig. 1): by altering endogenous serotonin levels in embryonic tissues, alteration of developmental signaling through modulation of electrogenic ion channels, and perturbation of calcium signaling pathways. Also, the impact of maternal depression and the effectiveness and risk of SSRIs in preventing or treating depression in pregnant women are discussed. The safety of prescribing SSRIs to treat depression and related conditions in women of childbearing age is of paramount public health importance, given the potentially serious outcomes for the unborn child.

\section{The Importance of Serotonin for Normal Embryonic Development}

Serotonin is not only a neurotransmitter but also a profoundly important medium for cell to cell communication among many cell types during embryogenesis. ${ }^{25-27}$ It has been implicated in several developmental events in addition to its roles in regulation of the nervous system. ${ }^{28-43}$ Most of the data on serotonin's role during embryogenesis are derived from model systems, in which definitive functional experiments can be performed that are impossible in human embryos for ethical reasons. It should be kept in mind that the fundamental mechanisms of cell biology and developmental pathways are highly conserved among vertebrate species; this is why organisms from yeast, to fruit fly, and to frog are responsible for many breakthroughs in human biomedicine (including birth defects, stem cell biology, and cancer). A range of animal models, including mammals such as rodent and rabbit, together with nonmammalian animals, such as Xenopus (frog), chicks, and zebrafish, provide vital information regarding the common and evolutionarily ancient mechanisms that orchestrate individual cell behaviors essential for normal development.

The embryo's serotonin pool derives from two sources: zygotic and maternal. Mammalian embryos generate their own serotonin very early, long before the nervous system appears. For example, mouse embryonic stem cells synthesize 5-HT, ${ }^{44}$ and both 5-HT and SERT are found in oocytes and cleavage-stage embryos of many species. ${ }^{45,46}$ Moreover, serotonin generated by the mother is passed on to the developing embryo through placental uptake and transport. ${ }^{43}$ Recent work has shown that serotonin is a key signaling molecule and is a medium for communication among cells during embryogenesis. ${ }^{28,29,35,36,42,47}$ Thus, appropriate signaling requires a delicate balance and correct concentrations

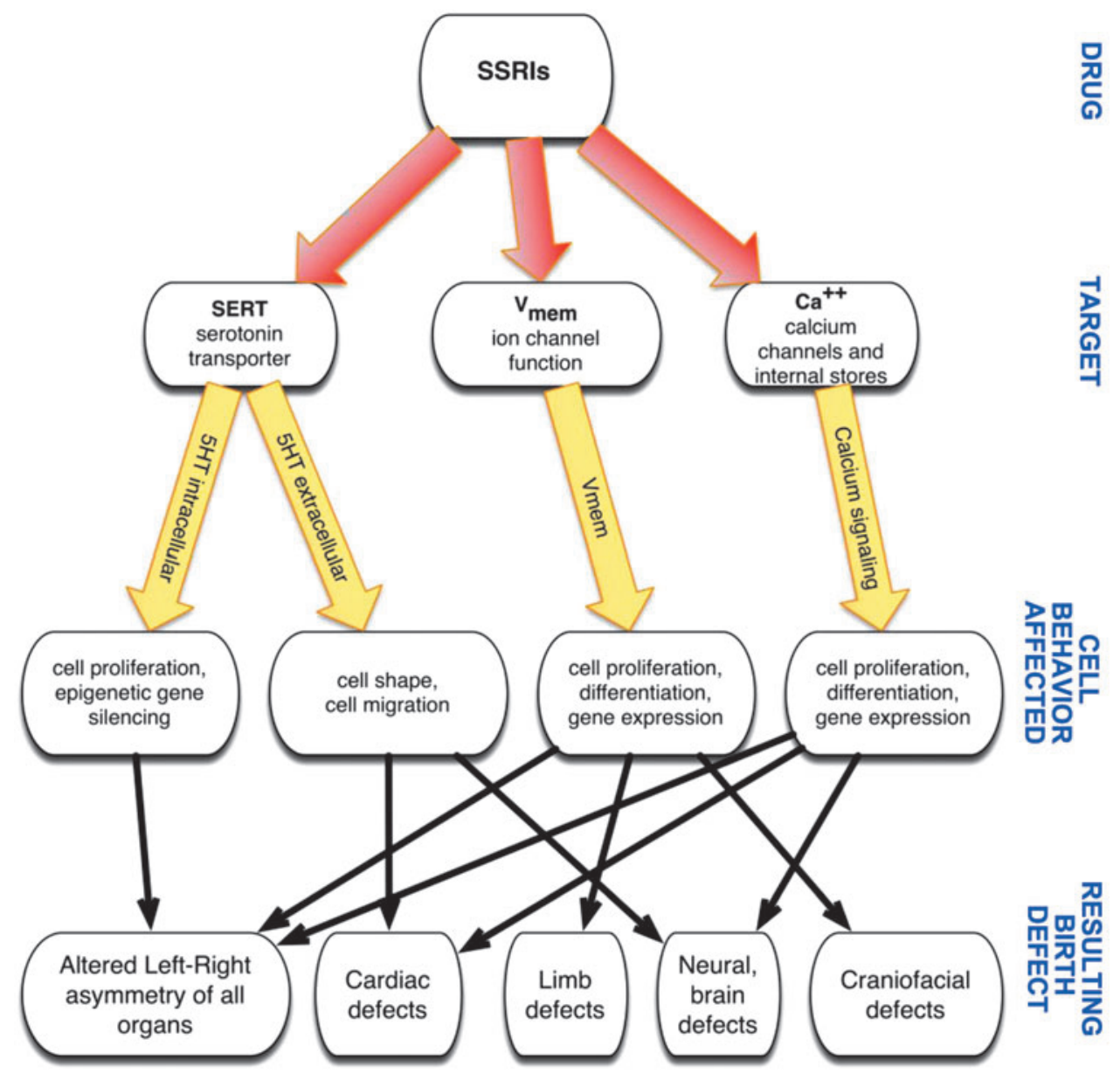

FIG. 1. Three types of mechanisms by which SSRIs can affect development. SSRIs, selective serotonin reuptake inhibitors. 
of serotonin in specific locations. Total 5-HT levels measured in blood are not sufficient to detect imbalances in this type of signaling because the relevant levels are within and adjacent to key cell types within the embryo and not in the maternal or fetal circulations. The fact that SSRIs readily cross the placenta ${ }^{48}$ and the fact that these drugs are designed to alter extracellular concentrations of 5-HT create a recipe for dis- rupting these delicate balances of the neurotransmitter and, hence, its ability to act as a signaling molecule.

Serotonin signals in two basic modes. In the extracellular mode (Fig. 2A), 5-HT arrives at the surface of target cells by diffusion from external locations and activates any of a family of seven extracellular serotonin receptors. ${ }^{49}$ The serotonin source can be remote cell types, ${ }^{29}$ or may indeed be

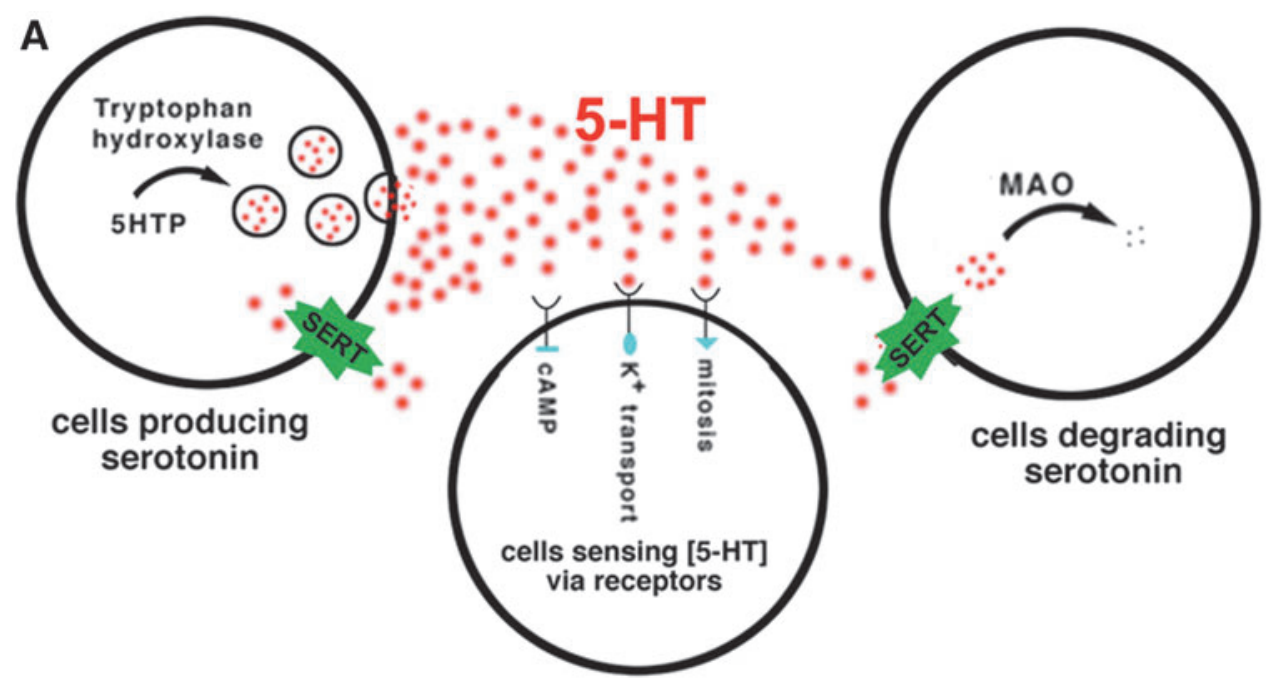

B

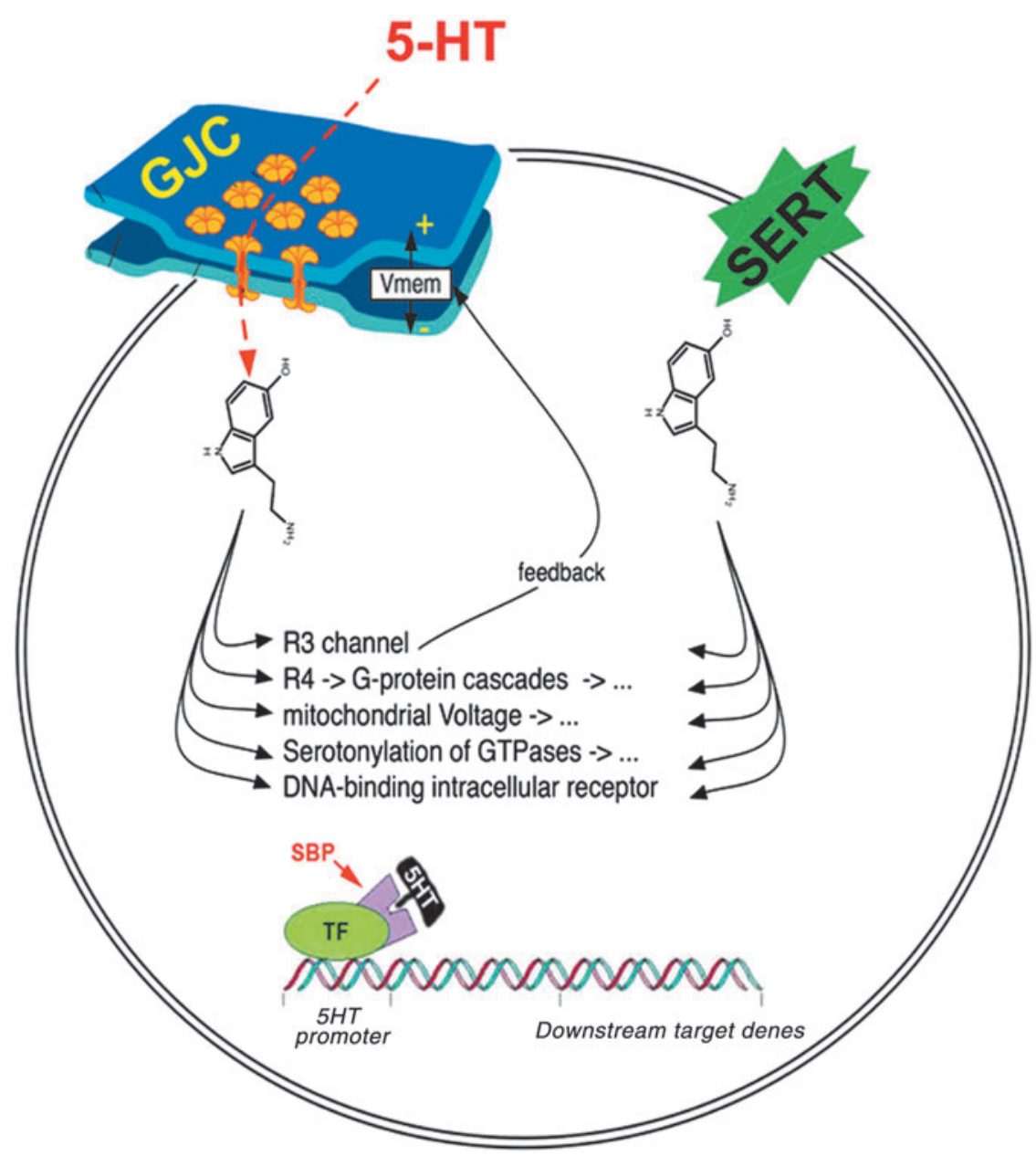

FIG. 2. Two basic modes for serotonin signals. (A) Extracellular mode. (B) Intracellular mode. 
secreted and received by the same cell (autocrine signaling). In the intracellular mode (Fig. 2B), serotonin arrives intracellularly through SERT-mediated import or through gap junction channels with neighboring cells. ${ }^{36,50-56}$ Levels of intracellular serotonin control cell division, ${ }^{57}$ cytoskeletal dynamics, ${ }^{58-60}$ second messengers (adenylate cyclase and histone deacetylase), ${ }^{61-63}$ and developmental gene expression. This occurs through binding to intracellular serotonin binding proteins, ${ }^{64}$ including Mad3 and 5-HT-R2, ${ }^{65,66}$ and by serotonylation of a variety of key molecules. ${ }^{67-70}$

Developmental serotonin signaling participates in a number of patterning events. One is establishment of body organ laterality - the invariant positioning of the visceral organs and heart. Consistent left-right (LR) asymmetry is a highly conserved feature in amphibians, reptiles, birds, fish, and mammals, all of which orient their hearts and visceral organs with the same biases in placement and morphology. In fact, the most basic cell signals for establishing laterality are conserved among many diverse species, including plants, nematodes, frogs, and humans. ${ }^{47,71}$ This conservation is important because it means that the basic mechanisms of LR asymmetry can be readily studied in model organisms. ${ }^{72}$ Errors in establishing laterality result in heterotaxy and include an important class of human birth defects with serious medical implications for the patient. ${ }^{73-76}$ It has been shown in chick and frog models that serotonergic signaling is required for the left and right sides of the body to acquire their identity and properly orient asymmetric organs such as the heart, stomach, liver, and others. $^{28,35,36,42,65,77-79}$ In addition, serotonergic signaling controls cell proliferation, ${ }^{80-85}$ regulation of cell shape and cell movement patterns, ${ }^{29,47,86-89}$ neurogenesis and brain patterning, ${ }^{90,91}$ heart morphogenesis, ${ }^{92}$ eye development, ${ }^{93}$ and craniofacial morphogenesis. ${ }^{39,94-96}$

SSRIs can block 5-HT uptake by the ectoplacental cone (early placenta in rodents) and placenta. ${ }^{43}$ Importantly, the SERT, a membrane protein that transports serotonin across cell membranes, acts as a key regulator of serotonin availability both inside and outside of cells. Although the name "reuptake inhibitor" for compounds that block SERT focuses on transport of serotonin into cells, SERT can also run in reverse to provide a source of serotonin to surrounding cells. ${ }^{97,98}$ This process is key to the regulation of certain kinds of stem cell derivatives. ${ }^{29}$ Thus, SSRIs affect mechanisms dependent on extracellular serotonin (mediated by plasma membrane receptor types 1-7) and mechanisms dependent on intracellular serotonin (epigenetic marking through HDAC1 and serotonylation of other signaling molecules).

Not only the mature nervous system but also many early embryonic cells utilize serotonin as a signaling messenger. ${ }^{59,60,99-102}$ Thus, by design and purpose, any of the class of SSRI drugs will profoundly affect the concentrations of this key molecule and thus the 5-HT-dependent signaling that is necessary for completing normal embryogenesis.

\section{Bioelectricity: A Teratogenic Mechanism for SSRIs in Addition to Serotonergic Pathways}

There is another mode of action by which SSRIs can perturb embryogenesis, distinct from the primary effects on SERT and serotonin levels. A number of studies have shown that SSRIs can bind to and modulate the activity of numerous ion channels in mammalian cells, including sodium, chloride, and potassium channels. ${ }^{103-115}$ Binding to these channels is relevant to the origin of birth defects because ion channel activity, such as serotonergic signaling, is not only a function of the nervous system but also a major mechanism for coordinating cell processes during embryonic morphogenesis of many organ systems. ${ }^{116,117}$

Data on developmental bioelectricity reveal that ion channels set up precisely patterned endogenous electric fields and voltage gradients regulating the formation of the heart, limb, brain, eye, and face. ${ }^{118-127}$ Human channelopathies (mutations disrupting bioelectric signaling) have revealed how disruption of ion channels can play a role in the causation of birth defects, including Andersen-Tawil syndrome, ${ }^{128,129}$ urogenital malformations, ${ }^{130,131}$ Angelman syndrome, ${ }^{132,133}$ Beckwith-Wiedemann syndrome, ${ }^{134-136}$ and defects of the face, ${ }^{137}$ heart, central nervous system, and neck. ${ }^{138}$ Recently, Gelb and coworkers ${ }^{139}$ discovered numerous ion channel mutations, including some involving channels directly modified by SSRIs, which result in birth defects of the heart (including laterality defects predicted by earlier work in frogs $\mathrm{s}^{28,35,36,42,140-142}$ ) and of the limb in mouse embryos. These data clearly confirm that the results obtained from frog models are directly relevant to mammalian development.

Transmembrane resting potentials (determined by specific ion channels) regulate proliferation and differentiation in a range of somatic and stem cell populations in vivo. ${ }^{126,143}$ The known interactions of SSRIs with sodium, potassium, and chloride ion channels ${ }^{103,104,106,107,109-111,113-115}$ suggest the likelihood that SSRI exposure of the fetus will perturb the fine-tuned bioelectrical signaling that enables individual cells to differentiate and arrange themselves in correct anatomical structures. $^{144}$

Based on these effects of 5-HT as a signal molecule potentially regulating development of a variety of organ systems through effects on general cell processes, such as proliferation and migration, it is easy to understand how SSRIs can cause multiple types of birth defects. In fact, this outcome appears to be exactly what occurs as shown by epidemiological studies. ${ }^{5-9,11,13-15,145-147}$ In turn, this multiplicity of birth defects then "dilutes" the data because incidences of any single defect may be low, making it difficult to identify statistically significant associations between in utero drug exposure and teratogenicity. However, the "array" of defects observed after exposure to SSRIs may represent a single classification of abnormalities with a common origin, hence a pattern of malformations.

For example, as stated previously, 5-HT is an important signaling molecule for establishing laterality by specifying the left-right (LR) axis on approximately the 14-16th days of gestation in humans (postconception). ${ }^{28,35,36,42,65,77-79}$ The establishment of this axis is essential for normal development and disruptions in this process, as can be caused by SSRIs, resulting in heterotaxy. Individuals with this condition have abnormalities of positioning of organ systems, including the spleen, heart, liver, and gut, and a wide variety of birth defects. ${ }^{75,148-152}$ The most sensitive organ to disruptions in laterality signaling is the heart ${ }^{73,151}$ and virtually every type of heart defect can occur when this signaling is altered, including atrial septal defect, ventricular septal defect, double outlet right ventricule, hypoplastic left ventricles, hypoplastic right 
ventricles, tetralogy of Fallot, single ventricle, atrial inversions and isomerisms, ventricular inversions, and transposition of the great arteries among others. ${ }^{73,149,153-155}$ A variety of other defects may also occur, particularly vascular defects, such as total anomalous pulmonary venous return. ${ }^{14,156}$ There is also a link between laterality abnormalities and midline defects that has been documented in the clinical literature since at least the mid 1990s. All types of midline defects have been observed in patients with laterality abnormalities, including neural tube defects, cleft lip and palate, gastroschisis, omphalocele, anal atresia and stenosis, and caudal dysgenesis. ${ }^{75,148-152,156}$ In fact, midline defects so commonly occur when laterality signaling is disrupted that if a patient has a midline defect, it has been estimated that they are 3 times more likely to have a laterality issue as compared with patients without a midline defect, and 100 more times than the general population. ${ }^{148,151}$ Furthermore, because many patients are never specifically assessed for laterality issues, these rates are likely under-reported. More importantly, individuals with midline defects do not require laterality abnormalities to be classified as having disrupted laterality signaling as the primary etiology of their midline malformation. This point has been proven in studies of family members with known mutations to laterality genes. In such families, a high incidence of family members exhibit only a single midline malformation, such as cleft palate or a neural tube defect, with no other abnormality. ${ }^{151,152,156}$ The reason that midline defects are common is probably due to the fact that as development proceeds, the different axes, including the anterior-posterior (cranio-caudal), dorso-ventral, and LR, must be coordinated in specifying the origin and position of the different organ systems. ${ }^{152,157-159}$ Therefore, if one axis, such as the LR, is abnormal, it disrupts the coordinated effort and results in a variety of defects, some of which might not appear to be related directly to effects on the targeted axis. Hence, a midline defect might occur due to a disruption in laterality signaling. Thus, the SSRIs may produce a variety of birth defects through a common mechanism of altering 5-HT concentrations and through a common pathway of disrupting 5-HT signaling responsible for establishing the LR axis at 14-16 days of gestation. This explanation readily explains the variety of seemingly unrelated defects seen at birth after SSRI exposure in utero.

\section{SSRIs and Major Congenital Malformations in Humans}

Depressive symptoms are common during pregnancy, and SSRIs are the most frequently used antidepressants to treat pregnant women. ${ }^{21,160,161}$ Studies concerning the adverse effects of SSRI exposure during gestation on the developing fetus have indicated an increased risk of various congenital malformations, $2,5-10,18$ but inconsistencies between study results remain. ${ }^{11-13,162,163}$ These could potentially be explained by indication bias wherein the effect of the drug and the indication are correlated and not fully accounted for, ${ }^{6,145,164}$ or misclassification bias wherein exposure and/or outcome assessment have not been validated. ${ }^{165}$

Gestational use of SSRI has been associated with an increased risk of various major congenital malformations. 2,5-14,18 $^{-1}$ This has been repeatedly shown in large well-designed population-based studies with sufficient statistical power. Indeed, over the past 20 years, data on the risk of malformations associated with intrauterine exposure to SSRI have been accumulating, even more so after 2005, when the warning on the risk of heart defects associated with paroxetine exposure during pregnancy was issued. ${ }^{166}$ Although the magnitude of the risk varies from one study to another, and between organ systems, it remains that as early as the mid' 90 s, sufficient signals on the risk of major congenital malformations on human pregnancy exposures to SSRIs have been available.

Overall, SSRIs as a class and SSRI-specific drugs increase the risk of major congenital malformation by at least $30 \%$ during pregnancy $\left(30-130 \%\right.$ increase in risk); ${ }^{2,7,9,10,13,15,18}$ the risk also increases with increasing dosage, which is supportive of a dose-response relationship, ${ }^{6,15}$ and longer duration of use during pregnancy, which is consistent with a cumulative effect. ${ }^{10}$ Although some studies lack statistical power, the majority of risk ratio estimates are $>1$, indicating an increase in risk. Even after considering the potential for bias, confounding and chance finding, the evidence-based literature demonstrates that prenatal exposure to SSRIs as a class causes an increased risk of congenital malformations in infants exposed in utero during the critical developmental time period. Given that major malformations are rare, more weight should be put on repetitions of findings or defects with known mechanisms of action than statistical significance, which solely depends on the number of exposed cases. ${ }^{164}$

SSRIs as a class increase the risk of major cardiac malformation by at least $60 \%$ as compared with nonuse during pregnancy. ${ }^{2,7,9,11,14,15,18,146}$ The published peer-reviewed evidence on sertraline, fluoxetine, citalopram, escitalopram, and paroxetine consistently demonstrates an increase in the risk of cardiac malformation from a $9 \%$ increased risk to more than four times the risk seen in nonusers. Although some cardiac defects are rarer and would require a very large sample size, which would be very difficult to acquire, there is evidence on some of the specific types of cardiac defects. Hence, SSRI as a class and SSRI-specific drug use during gestation have been associated with an increased risk of atrial and ventricular septal defects, ${ }^{2,5-9,11,14,15,18,145,164}$ right and left ventricular outflow track obstruction, ${ }^{5,8,18}$ conotruncal defects, ${ }^{5,8}$ transposition of the great arteries, ${ }^{5}$ tetralogy of Fallot, ${ }^{5}$ pulmonary valve stenosis, ${ }^{5}$ and patent ductus arteriosis. ${ }^{14}$

SSRIs have also been shown to increase the risk of craniosynostosis (odds ratios range from 1.94 to 2.5). ${ }^{2,5,8,15,145}$ Of note, the critical period of development for craniosynostosis may extend beyond the first trimester as shown by Alwan et al. ${ }^{5}$ who estimated a $90 \%$ increase in risk associated with second and third trimester exposure to SSRIs. However, Berard et al. ${ }^{145}$ showed that exposure at any time during pregnancy did not change findings. SSRI as a class also increases the risk of gastrointestinal defects (omphalocele, gastroschisis, esophageal atresia, anal atresia, hypertrophic pyloric stenosis, and vesicoureteric reflux $)^{5,8,14,15}$; neural tube defects (anencephaly and spina bifida) $)^{5,8,11}$; cleft lip with or without palate $e^{8,11,14}$; limb defects ${ }^{5,8,14,167}$; and other defects such as diaphragmatic hernia, ${ }^{5,8}$ hypospadias, ${ }^{8}$ undescended testis, ${ }^{8}$ and cystic kidney disease. ${ }^{14}$ All of these phenotypes are potential outcomes of perturbed serotonergic, bioelectrical, and calcium signaling. Furthermore, there is consistent evidence showing that SSRI as a class at least doubles the risk of persistent pulmonary hypertension of the newborn. ${ }^{168-171}$

Finally, SSRI as a class, and all SSRIs-specific drugs have been found to increase the risk of spontaneous abortions. ${ }^{3,4,172}$ 
Given that embryos with severe malformations are predominantly miscarried, ${ }^{164}$ this suggests that the true impact of antidepressants on the occurrence of defects is much higher than would be apparent from examination of embryos that survived to birth.

In summary, SSRIs considered separately or as a class have consistently been shown to increase the risk of major congenital malformations in general, and major organ system malformations specifically, even after considering the different magnitude of effects reported in studies. Defects observed at birth have similar embryonic origins and can be considered a pattern of malformations as already explained.

\section{The Role of Depression}

Recent reviews of prenatal mental health issues note that $35 \%$ of pregnant women have depressive symptoms and there are claims that $10 \%$ of them are depressed. ${ }^{173}$ One problem with this formulation is that having symptoms, even meeting every single one of the operational criteria for depression, does not necessarily mean a person is depressed. The point prevalence of major depression is $3.8 \%$ at the end of the first trimester, $4.9 \%$ at the end of the second trimester, and $3.1 \%$ at the end of the third trimester of pregnancy rather than the 10 $15 \%$ routinely reported. ${ }^{174}$ When arguments for treating prenatal depression are put forward, they state that untreated depression leads to smoking, alcohol and drug intake, poor self-care, suicide, and postnatal depression. ${ }^{175}$ They furthermore infer that there may be a direct toxic effect of untreated depression on the fetus. ${ }^{176}$ Finally, they point to effects on the development of the child in later life, arguing that these are substantial and deleterious. ${ }^{177}$ There are no known direct toxic effects of prenatal depression on the fetus. There is no known endocrine change linked to the majority of common nervous disorders that affect pregnant women that could affect the fetus. Maternal depression during pregnancy is not associated with the risk of congenital malformation, hence is not a risk factor for malformations. However, lifestyles associated with maternal depression, such as smoking, ${ }^{178}$ alcohol use, ${ }^{179}$ and lack of folic acid use,${ }^{180}$ have been implicated in the occurrence of major congenital malformations. Therefore, maternal depression is often used as a proxy for associated lifestyles.

Mothers who are depressed during pregnancy are, however, at increased risk of postpartum depression, ${ }^{181}$ and have lower mother-to-child attachment after delivery. ${ }^{182}$ If prenatal depression leads to a postnatal depression, there is always the opportunity to treat the depressive disorder vigorously at that time without risk to the fetus. Nevertheless, depression should be monitored during gestation and appropriate treatment (exercise and psychotherapy) ${ }^{183,184}$ should be considered. Furthermore, SSRIs are transferred to breast milk when used during the postnatal period, and thus have the potential to impact newborns during this time window.

\section{Effectiveness of SSRIs During Pregnancy}

Until the advent of SSRIs, the term depression in general referred to a more serious condition than major depressive disorder (MDD) now refers to. This more serious condition was originally called melancholia, later becoming endogenous depression. We know little about the risks of leaving classic or severe depressive disorders of this type untreated.
Melancholia is extremely rare in women who are pregnant, or in women of childbearing age. SSRIs are not given for classic or severe depressive disorders since the drugs are not effective in treating these conditions. These drugs are less effective than older antidepressants such as clomipramine for more severe depressive disorders. SSRIs are marketed for and given to women with anxiety and depressive symptoms. The lack of evidence concerning the efficacy or effectiveness of SSRI therapy, together with the fact that numerous studies have documented their detrimental effects on embryonic and fetal development mandates that alternative nonpharmacological interventions should be recommended for pregnant women with a resort to medication being a secondary option. At present, little consideration is given to nonpharmacological treatments with proven efficacy, such as exercise ${ }^{183}$ or psychotherapy. ${ }^{184}$

In 2006, the FDA held hearings on the issue of warnings regarding suicidality based on data from adult trials of antidepressants including all SSRIs. These trials in total contained close to 100,000 patients, $>50,000$ of whom were depressed patients. Aside from the question of suicidal acts, data from all short-term placebo-controlled adult trials for MDD for the past 15-20 years show that antidepressants in general have minimal effectiveness. When data from all randomized trials are combined, 5 out of every 10 patients respond to the drugs, but in the same trials 4 out of every 10 patients respond to placebo. ${ }^{185}$ Therefore, only 1 in 10 patients put on treatment responds specifically to the drug they have been put on, whereas 5 out of 10 either fail to respond or respond adversely. ${ }^{185}$ The high placebo response means that in many cases, the natural history of depressive disorders is to resolve spontaneously; in other instances, diet and hygiene will provide effective treatments, or assistance from the patient's physician to help work out problems at home or at work will solve the issue. Therefore, evidence-based findings demonstrate that in all instances, not just in the case of pregnant patients, SSRIs are not an effective treatment protocol for depression and should only be used for patients who do not respond to a conservative approach. Furthermore, issues regarding efficacy and the potential for harming babies should be made clear to pregnant women so they can opt an alternative treatment.

In the event that a particular prenatal depression or anxiety state is judged to require active treatment rather than simply employing monitoring measures, treatments such as interpersonal therapy (IPT) and cognitive behavioral therapy, which for this level of severity are as efficacious as drug treatment, can be considered. Indeed, given the role of social factors associated with the nervous states found during pregnancy, IPT that originated as a treatment for postnatal depression would appear to be particularly suitable for prenatal disorders. ${ }^{186}$

For moderate to severe or melancholic depressive disorders, guidelines such as those issued by the National Institute for Health and Clinical Excellence (NICE) recommend tricyclic antidepressants rather than SSRIs. ${ }^{187}$

\section{Conclusion}

The Bradford Hill criteria ${ }^{188}$ are useful in evaluating causality between an exposure and an outcome. Although these criteria are used to assess causation, not all of them 
need to be fulfilled to establish general causation. Evidence indicates that SSRI use during pregnancy is interrupting and/or disturbing essential events during the embryonic stage and organogenesis, which initiates a cascade of events that are causing spontaneous abortions and major congenital malformations. Epidemiological evidence in humans is consistent, and findings have been replicated in different patient populations; a dose-response has also been established. Malformations identified that all have similar embryonic origins and thus demonstrate a pattern of malformation. Mechanistic data unequivocally demonstrate that three major pathways known to be crucial for patterning of many embryonic organ systems, serotonergic signaling, bioelectric signaling, and calcium signaling all can be perturbed by SSRIs. The importance of these pathways in regulating cell behavior and multiple patterning systems during embryogenesis clearly suggests that SSRIs have the potential to cause birth defects. Given that all SSRIs have a similar mechanism of action, they should be considered as a class of compounds producing the same adverse effects on development.

Maternal depression has not been shown to increase the risk of major congenital malformation. The majority of depressed pregnant women have mild to moderate depression for which SSRIs are ineffective. At present, the risk-benefit ratio does not support the use of SSRIs during pregnancy. It is important that depression be monitored, but nonpharmacological therapies, such as exercise or psychotherapy, should be considered as a first line treatment during the gestational period. More broadly, because of the tight relationship between ion channel-mediated signaling and downstream neurotransmitter transduction steps operating during development, the mechanistic and epidemiological data on SSRIs serve as a primary example of the interplay between basic work in developmental bioelectricity and biomedicine.

\section{Acknowledgments}

M.L. is grateful for support by the March of Dimes and the American Heart Association.

\section{Authors' Contributions}

The concept and design of this study were done by A.B., M.L., T.S., and D.H.; the article was drafted by A.B., M.L., T.S., and D.H.; and critical revision of the article and important intellectual content were carried out by A.B., M.L., T.S., and D.H. All coauthors have reviewed and approved of the article before submission.

\section{Disclaimer}

The article has been submitted solely to this journal and is not published, in press, or submitted elsewhere.

\section{Author Disclosure Statement}

All authors are consultants for plaintiffs in the litigation involving antidepressants. A.B. is the holder of a research chair on Medications and Pregnancy from the Fonds de la Recherche du Québec-Santé (FRQS).

\section{References}

1. Wilson JG. Teratogenic effects of environmental chemicals. Fed Proc 1977;36:1698-1703.

2. Berard A, Zhao JP, Sheehy O. Antidepressant use during pregnancy and the risk of major congenital malformations in a cohort of depressed pregnant women: An updated analysis of the Quebec Pregnancy Cohort. BMJ Open 2017;7:e13372.

3. Nakhai-Pour HR, Broy P, et al. Use of antidepressants during pregnancy and the risk of spontaneous abortion. CMAJ 2010;182:1031-1037.

4. Einarson A, Choi J, Einarson TR, et al. Rates of spontaneous and therapeutic abortions following use of antidepressants in pregnancy: Results from a large prospective database. J Obstet Gynaecol Can 2009;31:452-456.

5. Alwan S, Reefhuis J, Rasmussen SA, et al. Use of selective serotonin-reuptake inhibitors in pregnancy and the risk of birth defects. N Engl J Med 2007;356:26842692.

6. Berard A, Ramos E, Rey E, et al. First trimester exposure to paroxetine and risk of cardiac malformations in infants: The importance of dosage. Birth Defects Res B Dev Reprod Toxicol 2007;80:18-27.

7. Kornum JB, Nielsen RB, Pedersen L, et al. Use of selective serotonin-reuptake inhibitors during early pregnancy and risk of congenital malformations: Updated analysis. Clin Epidemiol 2010;2:29-36.

8. Louik C, Lin AE, Werler MM, et al. First-trimester use of selective serotonin-reuptake inhibitors and the risk of birth defects. N Engl J Med 2007;356:2675-2683.

9. Pedersen LH, Henriksen TB, Vestergaard M, et al. Selective serotonin reuptake inhibitors in pregnancy and congenital malformations: Population based cohort study. BMJ 2009;339:b3569.

10. Wogelius P, Norgaard M, Gislum M, et al. Maternal use of selective serotonin reuptake inhibitors and risk of congenital malformations. Epidemiology 2006;17:701-704.

11. Malm H, Artama M, Gissler M, et al. Selective serotonin reuptake inhibitors and risk for major congenital anomalies. Obstet Gynecol 2011;118:111-120.

12. Nordeng H, van Gelder MM, Spigset O, et al. Pregnancy outcome after exposure to antidepressants and the role of maternal depression: Results from the Norwegian Mother and Child Cohort Study. J Clin Psychopharmacol 2012; 32:186-194.

13. Reis M, Kallen B. Delivery outcome after maternal use of antidepressant drugs in pregnancy: An update using Swedish data. Psychol Med 2010;40:1723-1733.

14. Colvin L, Slack-Smith L, Stanley FJ, et al. Dispensing patterns and pregnancy outcomes for women dispensed selective serotonin reuptake inhibitors in pregnancy. Birth Defects Res A Clin Mol Teratol 2011;91:142-152.

15. Jimenez-Solem E, Andersen JT, Petersen M, et al. Exposure to selective serotonin reuptake inhibitors and the risk of congenital malformations: A nationwide cohort study. BMJ Open 2012;2; DOI:10.1136/bmjopen-2012001148 .

16. Ramos E, St-Andre M, Berard A. Association between antidepressant use during pregnancy and infants born small for gestational age. Can J Psychiatry 2010;55:643-652.

17. Huybrechts KF, Sanghani RS, Avorn J, et al. Preterm birth and antidepressant medication use during pregnancy: A systematic review and meta-analysis. PLoS One 2014;9:e92778. 
18. Berard A, Iessa N, Chaabane S, et al. The risk of major cardiac malformations associated with paroxetine use during the first trimester of pregnancy: A systematic review and meta-analysis. Br J Clin Pharmacol 2016;81: 589-604.

19. Healy D, Le Noury J, Mangin D. Links between serotonin reuptake inhibition during pregnancy and neurodevelopmental delay/spectrum disorders: A systematic review of epidemiological and physiological evidence. Int J Risk Saf Med 2016;28:125-141.

20. Boukhris T, Berard A. Selective serotonin reuptake inhibitor use during pregnancy and the risk of autism spectrum disorders: A review. J Pediatr Genet 2015;4:84-93.

21. Ramos E, Oraichi D, Rey E, et al. Prevalence and predictors of antidepressant use in a cohort of pregnant women. BJOG 2007;114:1055-1064.

22. Berard A, Gaedigk A, Sheehy O, et al. Association between CYP2D6 genotypes and the risk of antidepressant discontinuation, dosage modification and the occurrence of maternal depression during pregnancy. Front Pharmacol 2017;8:402.

23. Shorter E. The 25th anniversary of the launch of Prozac gives pause for thought: Where did we go wrong? $\mathrm{Br} \mathrm{J}$ Psychiatry 2014;204:331-332.

24. FDA Established Pharmacologic Class (EPC). www.fda .gov/downloads/Drugs/GuidanceComplianceRegulatory Information/LawsActsandRules/UCM428333.pdf (last accessed June 15, 2018).

25. Buznikov GA, Lambert HW, Lauder JM. Serotonin and serotonin-like substances as regulators of early embryogenesis and morphogenesis. Cell Tissue Res 2001;305: 177-186.

26. Buznikov GA, Shmukler YB. Possible role of "prenervous" neurotransmitters in cellular interactions of early embryogenesis: A hypothesis. Neurochem Res 1981; 6:55-68.

27. Levin M, Buznikov GA, Lauder JM. Of minds and embryos: Left-right asymmetry and the serotonergic controls of pre-neural morphogenesis. Dev Neurosci 2006;28:171185.

28. Adams DS, Robinson KR, Fukumoto T, et al. Early, $\mathrm{H}+-\mathrm{V}$-ATPase-dependent proton flux is necessary for consistent left-right patterning of non-mammalian vertebrates. Development 2006;133:1657-1671.

29. Blackiston D, Adams DS, Lemire JM, et al. Transmembrane potential of GlyCl-expressing instructor cells induces a neoplastic-like conversion of melanocytes via a serotonergic pathway. Dis Model Mech 2011;4:67-85.

30. Choi DS, Birraux G, Launay JM, et al. The human serotonin 5-HT2B receptor: Pharmacological link between 5-HT2 and 5-HT1D receptors. FEBS Lett 1994;352:393-399.

31. Choi DS, Colas JF, Kellermann O, et al. The mouse 5HT2B receptor: Possible involvement in trophic functions of serotonin. Cell Mol Biol (Noisy-le-grand) 1994;40: 403-411.

32. Choi DS, Kellermann O, Richard S, et al. Mouse 5-HT2B receptor-mediated serotonin trophic functions. Ann N Y Acad Sci 1998;861:67-73.

33. Choi DS, Maroteaux L. Immunohistochemical localisation of the serotonin 5-HT2B receptor in mouse gut, cardiovascular system, and brain. FEBS Lett 1996;391: 45-51.

34. Choi DS, Ward SJ, Messaddeq N, et al. 5-HT2B receptormediated serotonin morphogenetic functions in mouse cranial neural crest and myocardiac cells. Development 1997;124:1745-1755.

35. Fukumoto T, Blakely R, Levin M. Serotonin transporter function is an early step in left-right patterning in chick and frog embryos. Dev Neurosci 2005;27:349-363.

36. Fukumoto T, Kema IP, Levin M. Serotonin signaling is a very early step in patterning of the left-right axis in chick and frog embryos. Curr Biol 2005;15:794-803.

37. Launay JM, Birraux G, Bondoux D, et al. Ras involvement in signal transduction by the serotonin 5-HT2B receptor. J Biol Chem 1996;271:3141-3147.

38. Rea AC, Vandenberg LN, Ball RE, et al. Light-activated serotonin for exploring its action in biological systems. Chem Biol 2013;20:1536-1546.

39. Shuey DL, Sadler TW, Lauder JM. Serotonin as a regulator of craniofacial morphogenesis: Site specific malformations following exposure to serotonin uptake inhibitors. Teratology 1992;46:367-378.

40. Shuey DL, Sadler TW, Tamir H, et al. Serotonin and morphogenesis. Transient expression of serotonin uptake and binding protein during craniofacial morphogenesis in the mouse. Anat Embryol (Berl) 1993;187:75-85.

41. Shuey DL, Yavarone M, Sadler TW, et al. Serotonin and morphogenesis in the cultured mouse embryo. Adv Exp Med Biol 1990;265:205-215.

42. Vandenberg LN, Lemire JM, Levin M. Serotonin has early, cilia-independent roles in Xenopus left-right patterning. Dis Model Mech 2013;6:261-268.

43. Yavarone MS, Shuey DL, Sadler TW, et al. Serotonin uptake in the ectoplacental cone and placenta of the mouse. Placenta 1993;14:149-161.

44. Walther DJ, Bader M. Serotonin synthesis in murine embryonic stem cells. Brain Res Mol Brain Res 1999;68: $55-63$.

45. Amireault P, Dube F. Serotonin and its antidepressantsensitive transport in mouse cumulus-oocyte complexes and early embryos. Biol Reprod 2005;73:358-365.

46. Dube F, Amireault P. Local serotonergic signaling in mammalian follicles, oocytes and early embryos. Life Sci 2007;81:1627-1637.

47. Lobikin M, Chernet B, Lobo D, et al. Resting potential, oncogene-induced tumorigenesis, and metastasis: The bioelectric basis of cancer in vivo. Phys Biol 2012;9:065002.

48. Rampono J, Simmer K, Ilett KF, et al. Placental transfer of SSRI and SNRI antidepressants and effects on the neonate. Pharmacopsychiatry 2009;42:95-100.

49. Noda M, Higashida $H$, Aoki $S$, et al. Multiple signal transduction pathways mediated by 5 -HT receptors. Mol Neurobiol 2004;29:31-39.

50. Blomstrand F, Aberg ND, Eriksson PS, et al. Extent of intercellular calcium wave propagation is related to gap junction permeability and level of connexin-43 expression in astrocytes in primary cultures from four brain regions. Neuroscience 1999;92:255-265.

51. Esser AT, Smith KC, Weaver JC, et al. Mathematical model of morphogen electrophoresis through gap junctions. Dev Dyn 2006;235:2144-2159.

52. Gairhe S, Bauer NN, Gebb SA, et al. Serotonin passes through myoendothelial gap junctions to promote pulmonary arterial smooth muscle cell differentiation. Am J Physiol Lung Cell Mol Physiol 2012;303:L767-L777.

53. Hou M, Li Y, Paul DL. A novel, highly sensitive method for assessing gap junctional coupling. J Neurosci Methods 2013;220:18-23. 
54. Sun JD, Liu Y, Yuan YH, et al. Gap junction dysfunction in the prefrontal cortex induces depressive-like behaviors in rats. Neuropsychopharmacology 2012;37:1305-1320.

55. Wolszon LR, Gao WQ, Passani MB, et al. Growth cone "collapse" in vivo: Are inhibitory interactions mediated by gap junctions? J Neurosci 1994;14:999-1010.

56. Zhang Y, Levin M. Particle tracking model of electrophoretic morphogen movement reveals stochastic dynamics of embryonic gradient. Dev Dyn 2009;238:19231935.

57. Berg DA, Belnoue L, Song $\mathrm{H}$, et al. Neurotransmittermediated control of neurogenesis in the adult vertebrate brain. Development 2013;140:2548-2561.

58. Buskohl PR, Sun MJ, Thompson RP, et al. Serotonin potentiates transforming growth factor-beta3 induced biomechanical remodeling in avian embryonic atrioventricular valves. PLoS One 2012;7:e42527.

59. Liu Y, Wei L, Laskin DL, et al. Role of protein transamidation in serotonin-induced proliferation and migration of pulmonary artery smooth muscle cells. Am J Respir Cell Mol Biol 2011;44:548-555.

60. Pai VP, Marshall AM, Hernandez LL, et al. Altered serotonin physiology in human breast cancers favors paradoxical growth and cell survival. Breast Cancer Res 2009; 11:R81.

61. Kretsovali A, Hadjimichael C, Charmpilas N. Histone deacetylase inhibitors in cell pluripotency, differentiation, and reprogramming. Stem Cells Int 2012;2012:184154.

62. Menegola E, Di Renzo F, Broccia ML, et al. Inhibition of histone deacetylase as a new mechanism of teratogenesis. Birth Defects Res C Embryo Today 2006;78:345-353.

63. Tresguerres M, Levin LR, Buck J. Intracellular cAMP signaling by soluble adenylyl cyclase. Kidney Int 2011; 79:1277-1288.

64. Del Rio MJ, Velez-Pardo C, Ebinger G, et al. Serotonin binding proteins "SBP": Target proteins and tool for in vitro neurotoxicity studies. Gen Pharmacol 1995;26: 1633-1641.

65. Carneiro K, Donnet C, Rejtar T, et al. Histone deacetylase activity is necessary for left-right patterning during vertebrate development. BMC Dev Biol 2011;11:29.

66. Cornea-Hebert V, Riad M, Wu C, et al. Cellular and subcellular distribution of the serotonin 5-HT2A receptor in the central nervous system of adult rat. J Comp Neurol 1999;409:187-209.

67. Hummerich R, Schloss P. Serotonin-more than a neurotransmitter: Transglutaminase-mediated serotonylation of C6 glioma cells and fibronectin. Neurochem Int 2010; 57:67-75.

68. Paulmann N, Grohmann M, Voigt JP, et al. Intracellular serotonin modulates insulin secretion from pancreatic beta-cells by protein serotonylation. PLoS Biol 2009;7: e1000229.

69. Walther DJ, Peter JU, Winter S, et al. Serotonylation of small GTPases is a signal transduction pathway that triggers platelet alpha-granule release. Cell 2003;115: 851-862.

70. Watts SW, Priestley JR, Thompson JM. Serotonylation of vascular proteins important to contraction. PLoS One 2009; 4:e5682.

71. Lobikin M, Wang G, Xu J, et al. Early, nonciliary role for microtubule proteins in left-right patterning is conserved across kingdoms. Proc Natl Acad Sci U S A 2012;109: 12586-12591.
72. Levin M, Palmer AR. Left-right patterning from the inside out: Widespread evidence for intracellular control. Bioessays 2007;29:271-287.

73. Casey B. Two rights make a wrong: Human left-right malformations. Hum Mol Genet 1998;7:1565-1571.

74. Casey B, Hackett BP. Left-right axis malformations in man and mouse. Curr Opin Genet Dev 2000;10:257-261.

75. Kosaki K, Casey B. Genetics of human left-right axis malformations. Semin Cell Dev Biol 1998;9:89-99.

76. Peeters H, Devriendt K. Human laterality disorders. Eur J Med Genet 2006;49:349-362.

77. Beyer T, Danilchik M, Thumberger T, et al. Serotonin signaling is required for Wnt-dependent GRP specification and leftward flow in Xenopus. Curr Biol 2012;22:33-39.

78. Garic-Stankovic A, Hernandez M, Flentke GR, et al. A ryanodine receptor-dependent $\mathrm{Ca}(\mathrm{i})(2+)$ asymmetry at Hensen's node mediates avian lateral identity. Development 2008;135:3271-3280.

79. Vandenberg LN, Levin M. Polarity proteins are required for left-right axis orientation and twin-twin instruction. Genesis 2012;50:219-234.

80. Deraet M, Manivet P, Janoshazi A, et al. The natural mutation encoding a $\mathrm{C}$ terminus-truncated 5-hydroxytryptamine $2 \mathrm{~B}$ receptor is a gain of proliferative functions. Mol Pharmacol 2005;67:983-991.

81. Furrer K, Rickenbacher A, Tian Y, et al. Serotonin reverts age-related capillarization and failure of regeneration in the liver through a VEGF-dependent pathway. Proc Natl Acad Sci U S A 2011;108:2945-2950.

82. Gustafsson BI, Thommesen L, Stunes AK, et al. Serotonin and fluoxetine modulate bone cell function in vitro. J Cell Biochem 2006;98:139-151.

83. Lee SL, Wang WW, Lanzillo JJ, et al. Serotonin produces both hyperplasia and hypertrophy of bovine pulmonary artery smooth muscle cells in culture. Am J Physiol 1994; 266:L46-L52.

84. Lesurtel M, Graf R, Aleil B, et al. Platelet-derived serotonin mediates liver regeneration. Science 2006;312:104107.

85. Sari Y, Zhou FC. Serotonin and its transporter on proliferation of fetal heart cells. Int J Dev Neurosci 2003;21: 417-424.

86. Colas JF, Launay JM, Maroteaux L. Maternal and zygotic control of serotonin biosynthesis are both necessary for Drosophila germband extension. Mech Dev 1999;87:6776.

87. Colas JF, Launay JM, Vonesch JL, et al. Serotonin synchronises convergent extension of ectoderm with morphogenetic gastrulation movements in Drosophila. Mech Dev 1999;87:77-91.

88. Moiseiwitsch JR, Lauder JM. Serotonin regulates mouse cranial neural crest migration. Proc Natl Acad Sci U S A 1995;92:7182-7186.

89. Schaerlinger B, Launay JM, Vonesch JL, et al. Gain of affinity point mutation in the serotonin receptor gene 5HT2Dro accelerates germband extension movements during Drosophila gastrulation. Dev Dyn 2007;236:991999.

90. Cote F, Fligny C, Bayard E, et al. Maternal serotonin is crucial for murine embryonic development. Proc Natl Acad Sci U S A 2007;104:329-334.

91. Zhang Y, Benton JL, Beltz BS. 5-HT receptors mediate lineage-dependent effects of serotonin on adult neurogenesis in Procambarus clarkii. Neural Dev 2011;6:2. 
92. Nebigil CG, Choi DS, Dierich A, et al. Serotonin 2B receptor is required for heart development. Proc Natl Acad Sci U S A 2000;97:9508-9513.

93. De Lucchini S, Ori M, Cremisi F, et al. 5-HT2B-mediated serotonin signaling is required for eye morphogenesis in Xenopus. Mol Cell Neurosci 2005;29:299-312.

94. Bhasin N, LaMantia AS, Lauder JM. Opposing regulation of cell proliferation by retinoic acid and the serotonin2B receptor in the mouse frontonasal mass. Anat Embryol (Berl) 2004;208:135-143.

95. Lauder JM, Zimmerman EF. Sites of serotonin uptake in epithelia of the developing mouse palate, oral cavity, and face: Possible role in morphogenesis. J Craniofac Genet Dev Biol 1988;8:265-276.

96. Moiseiwitsch JR, Lauder JM. Regulation of gene expression in cultured embryonic mouse mandibular mesenchyme by serotonin antagonists. Anat Embryol (Berl) 1997;195:71-78.

97. Adams SV, DeFelice LJ. Flux coupling in the human serotonin transporter. Biophys J 2002;83:3268-3282.

98. Hilber B, Scholze P, Dorostkar MM, et al. Serotonintransporter mediated efflux: A pharmacological analysis of amphetamines and non-amphetamines. Neuropharmacology 2005;49:811-819.

99. Dizeyi N, Bjartell A, Nilsson E, et al. Expression of serotonin receptors and role of serotonin in human prostate cancer tissue and cell lines. Prostate 2004;59:328-336.

100. Meredith EJ, Holder MJ, Chamba A, et al. The serotonin transporter (SLC6A4) is present in B-cell clones of diverse malignant origin: Probing a potential anti-tumor target for psychotropics. FASEB J 2005;19:1187-1189.

101. Slominski A, Pisarchik A, Zbytek B, et al. Functional activity of serotoninergic and melatoninergic systems expressed in the skin. J Cell Physiol 2003;196:144-153.

102. Slominski A, Wortsman J, Tobin DJ. The cutaneous serotoninergic/melatoninergic system: Securing a place under the sun. FASEB J 2005;19:176-194.

103. Aldana BI, Sitges M. Sertraline inhibits pre-synaptic $\mathrm{Na}(+)$ channel-mediated responses in hippocampusisolated nerve endings. J Neurochem 2012;121:197-205.

104. Chien JM, Chou CT, Pan CC, et al. The mechanism of sertraline-induced $[\mathrm{Ca} 2+] \mathrm{i}$ rise in human $\mathrm{OC} 2$ oral cancer cells. Hum Exp Toxicol 2011;30:1635-1643.

105. Feuerbach D, Lingenhohl K, Dobbins P, et al. Coupling of human nicotinic acetylcholine receptors alpha 7 to calcium channels in GH3 cells. Neuropharmacology 2005; 48:215-227.

106. Fonseca-Magalhaes PA, Sousa DF, de Siqueira RJ, et al. Inhibitory effects of sertraline in rat isolated perfused kidneys and in isolated ring preparations of rat arteries. $\mathbf{J}$ Pharm Pharmacol 2011;63:1186-1194.

107. Fryer JD, Lukas RJ. Antidepressants noncompetitively inhibit nicotinic acetylcholine receptor function. J Neurochem 1999;72:1117-1124.

108. Huang CJ, Harootunian A, Maher MP, et al. Characterization of voltage-gated sodium-channel blockers by electrical stimulation and fluorescence detection of membrane potential. Nat Biotechnol 2006;24:439-446.

109. Huang CJ, Kuo DH, Chang KH, et al. Effect of the antidepressant sertraline on $\mathrm{Ca} 2+$ fluxes in Madin-Darby canine renal tubular cells. J Recept Signal Transduct Res 2009;29:342-348.

110. Kalyoncu NI, Ozyavuz R, Karaoglu S. Sertraline inhibits the contractile responses to noradrenaline, $\mathrm{KCl}$ and elec- trical field stimulation of rat isolated vas deferens. J Auton Pharmacol 1999;19:365-369.

111. Kobayashi T, Washiyama K, Ikeda K. Inhibition of $G$ protein-activated inwardly rectifying $\mathrm{K}+$ channels by different classes of antidepressants. PLoS One 2011;6:e28208.

112. Lee HA, Kim KS, Hyun SA, et al. Wide spectrum of inhibitory effects of sertraline on cardiac ion channels. Korean J Physiol Pharmacol 2012;16:327-332.

113. Maertens C, Droogmans G, Verbesselt R, et al. Block of volume-regulated anion channels by selective serotonin reuptake inhibitors. Naunyn Schmiedebergs Arch Pharmacol 2002;366:158-165.

114. Ohno Y, Hibino H, Lossin C, et al. Inhibition of astroglial Kir4.1 channels by selective serotonin reuptake inhibitors. Brain Res 2007;1178:44-51.

115. Wang GK, Mitchell J, Wang SY. Block of persistent late $\mathrm{Na}+$ currents by antidepressant sertraline and paroxetine. $\mathrm{J}$ Membr Biol 2008;222:79-90.

116. Bates E. Ion channels in development and cancer. Annu Rev Cell Dev Biol 2015;31:231-247.

117. Levin M, Martyniuk CJ. The bioelectric code: An ancient computational medium for dynamic control of growth and form. Biosystems 2018;164:76-93.

118. Hatten ME, Liem RK, Mason CA. Weaver mouse cerebellar granule neurons fail to migrate on wild-type astroglial processes in vitro. J Neurosci 1986;6:2676-2683

119. Levin M. Bioelectric mechanisms in regeneration: Unique aspects and future perspectives. Semin Cell Dev Biol 2009;20:543-556.

120. Levin M. Reprogramming cells and tissue patterning via bioelectrical pathways: Molecular mechanisms and biomedical opportunities. Wiley Interdiscip Rev Syst Biol Med 2013;5:657-676.

121. Levin M, Stevenson CG. Regulation of cell behavior and tissue patterning by bioelectrical signals: Challenges and opportunities for biomedical engineering. Annu Rev Biomed Eng 2012;14:295-323.

122. Patil N, Cox DR, Bhat D, et al. A potassium channel mutation in weaver mice implicates membrane excitability in granule cell differentiation. Nat Genet 1995;11:126-129.

123. Rakic P, Sidman RL. Sequence of developmental abnormalities leading to granule cell deficit in cerebellar cortex of weaver mutant mice. J Comp Neurol 1973;152:103-132.

124. Rakic P, Sidman RL. Weaver mutant mouse cerebellum: Defective neuronal migration secondary to abnormality of Bergmann glia. Proc Natl Acad Sci U S A 1973;70:240-244.

125. Sundelacruz S, Levin M, Kaplan DL. Role of membrane potential in the regulation of cell proliferation and differentiation. Stem Cell Rev 2009;5:231-246.

126. Tseng A, Levin M. Cracking the bioelectric code: Probing endogenous ionic controls of pattern formation. Commun Integr Biol 2013;6:e22595.

127. Teng GQ, Zhao X, Lees-Miller JP, et al. Homozygous missense N629D hERG (KCNH2) potassium channel mutation causes developmental defects in the right ventricle and its outflow tract and embryonic lethality. Circ Res 2008;103:1483-1491.

128. Bendahhou S, Donaldson MR, Plaster NM, et al. Defective potassium channel Kir2.1 trafficking underlies Andersen-Tawil syndrome. J Biol Chem 2003;278:5177951785.

129. Dahal GR, Rawson J, Gassaway B, et al. An inwardly rectifying $\mathrm{K}+$ channel is required for patterning. Development 2012;139:3653-3664. 
130. Uzun S, Gokce S, Wagner K. Cystic fibrosis transmembrane conductance regulator gene mutations in infertile males with congenital bilateral absence of the vas deferens. Tohoku J Exp Med 2005;207:279-285.

131. Wilschanski M, Dupuis A, Ellis L, et al. Mutations in the cystic fibrosis transmembrane regulator gene and in vivo transepithelial potentials. Am J Respir Crit Care Med 2006; 174:787-794.

132. Culiat CT, Stubbs LJ, Woychik RP, et al. Deficiency of the beta 3 subunit of the type A gamma-aminobutyric acid receptor causes cleft palate in mice. Nat Genet 1995;11: 344-346.

133. Galanopoulou AS. Mutations affecting GABAergic signaling in seizures and epilepsy. Pflugers Arch 2010;460: 505-523.

134. Lee MP, Ravenel JD, Hu RJ, et al. Targeted disruption of the Kvlqt1 gene causes deafness and gastric hyperplasia in mice. J Clin Invest 2000;106:1447-1455.

135. Moore ES, Ward RE, Escobar LF, et al. Heterogeneity in Wiedemann-Beckwith syndrome: Anthropometric evidence. Am J Med Genet 2000;90:283-290.

136. Weksberg R, Nishikawa J, Caluseriu O, et al. Tumor development in the Beckwith-Wiedemann syndrome is associated with a variety of constitutional molecular 11p15 alterations including imprinting defects of KCNQ1OT1. Hum Mol Genet 2001;10:2989-3000.

137. Gloyn AL, Pearson ER, Antcliff JF, et al. Activating mutations in the gene encoding the ATP-sensitive potassium-channel subunit Kir6.2 and permanent neonatal diabetes. N Engl J Med 2004;350:1838-1849.

138. Fonager K, Larsen H, Pedersen L, et al. Birth outcomes in women exposed to anticonvulsant drugs. Acta Neurol Scand 2000;101:289-294.

139. Pediatric Cardiac Genomics C, Gelb B, Brueckner M, et al. The Congenital Heart Disease Genetic Network Study: Rationale, design, and early results. Circ Res 2013; 112:698-706.

140. Aw S, Adams DS, Qiu D, et al. H,K-ATPase protein localization and Kir4.1 function reveal concordance of three axes during early determination of left-right asymmetry. Mech Dev 2008;125:353-372.

141. Aw S, Koster JC, Pearson W, et al. The ATP-sensitive $\mathrm{K}(+)$-channel (K(ATP)) controls early left-right patterning in Xenopus and chick embryos. Dev Biol 2010;346:39-53.

142. Morokuma J, Blackiston D, Levin M. KCNQ1 and $\mathrm{KCNE} 1 \mathrm{~K}+$ channel components are involved in early left-right patterning in Xenopus laevis embryos. Cell Physiol Biochem 2008;21:357-372.

143. Levin M. Molecular bioelectricity in developmental biology: New tools and recent discoveries: Control of cell behavior and pattern formation by transmembrane potential gradients. Bioessays 2012;34:205-217.

144. Hernandez-Diaz S, Levin M. Alteration of bioelectricallycontrolled processes in the embryo: A teratogenic mechanism for anticonvulsants. Reprod Toxicol 2014;47:111-114.

145. Berard A, Zhao JP, Sheehy O. Sertraline use during pregnancy and the risk of major malformations. Am J Obstet Gynecol 2015;212:795 e791-e795 e712.

146. Diav-Citrin O, Shechtman S, Weinbaum D, et al. Paroxetine and fluoxetine in pregnancy: A prospective, multicentre, controlled, observational study. Br J Clin Pharmacol 2008;66:695-705.

147. Bakker MK, Kerstjens-Frederikse WS, Buys CH, et al. First-trimester use of paroxetine and congenital heart de- fects: A population-based case-control study. Birth Defects Res A Clin Mol Teratol 2010;88:94-100.

148. Martinez-Frias ML, Urioste M, Bermejo E, et al. Primary midline developmental field. II. Clinical/epidemiological analysis of alteration of laterality (normal body symmetry and asymmetry). Am J Med Genet 1995;56:382-388.

149. Gebbia M, Ferrero GB, Pilia G, et al. X-linked situs abnormalities result from mutations in ZIC3. Nat Genet 1997; 17:305-308.

150. Ticho BS, Goldstein AM, Van Praagh R. Extracardiac anomalies in the heterotaxy syndromes with focus on anomalies of midline-associated structures. Am J Cardiol 2000;85:729-734.

151. Morelli SH, Young L, Reid B, et al. Clinical analysis of families with heart, midline, and laterality defects. Am J Med Genet 2001;101:388-392.

152. Bisgrove BW, Morelli SH, Yost HJ. Genetics of human laterality disorders: Insights from vertebrate model systems. Annu Rev Genomics Hum Genet 2003;4:1-32.

153. Ramsdell AF. Left-right asymmetry and congenital cardiac defects: Getting to the heart of the matter in vertebrate leftright axis determination. Dev Biol 2005;288:1-20.

154. Ramsdell AF, Bernanke JM, Trusk TC. Left-right lineage analysis of the embryonic Xenopus heart reveals a novel framework linking congenital cardiac defects and laterality disease. Development 2006;133:1399-1410.

155. Bamforth SD, Braganca J, Farthing CR, et al. Cited2 controls left-right patterning and heart development through a Nodal-Pitx2c pathway. Nat Genet 2004;36: 1189-1196.

156. Ware SM, Peng J, Zhu L, et al. Identification and functional analysis of ZIC3 mutations in heterotaxy and related congenital heart defects. Am J Hum Genet 2004;74: 93-105.

157. Levin M. Left-right asymmetry in embryonic development: A comprehensive review. Mech Dev 2005;122:3-25.

158. Takaoka K, Yamamoto M, Hamada H. Origin of body axes in the mouse embryo. Curr Opin Genet Dev 2007; 17 : 344-350.

159. Aw S, Levin M. Is left-right asymmetry a form of planar cell polarity? Development 2009;136:355-366.

160. Cooper WO, Willy ME, Pont SJ, et al. Increasing use of antidepressants in pregnancy. Am J Obstet Gynecol 2007; 196:544 e541-e545.

161. Jimenez-Solem E, Andersen JT, Petersen M, et al. Prevalence of antidepressant use during pregnancy in Denmark, a nation-wide cohort study. PLoS One 2013;8: e63034.

162. Huybrechts KF, Palmsten K, Avorn J, et al. Antidepressant use in pregnancy and the risk of cardiac defects. N Engl J Med 2014;370:2397-2407.

163. Margulis AV, Abou-Ali A, Strazzeri MM, et al. Use of selective serotonin reuptake inhibitors in pregnancy and cardiac malformations: A propensity-score matched cohort in CPRD. Pharmacoepidemiol Drug Saf 2013;22: 942-951.

164. Berard A. Paroxetine exposure during pregnancy and the risk of cardiac malformations: What is the evidence? Birth Defects Res A Clin Mol Teratol 2010;88:171-174.

165. Berard A, Chaabane S, Boukhris T. Antidepressant use in pregnancy and the risk of cardiac defects. N Engl J Med 2014;371:1167-1168.

166. FDA advising of risk of birth defects with Paxil. News release of the Food and Drug Administration, December 8, 2005 
www.fda.gov/NewsEvents/Newsroom/PressAnnouncements/ 2005/ucm108527.htm (last accessed June 15, 2018).

167. Yazdy MM, Mitchell AA, Louik C, et al. Use of selective serotonin-reuptake inhibitors during pregnancy and the risk of clubfoot. Epidemiology 2014;25:859-865.

168. Chambers CD, Hernandez-Diaz S, Van Marter LJ, et al. Selective serotonin-reuptake inhibitors and risk of persistent pulmonary hypertension of the newborn. N Engl J Med 2006;354:579-587.

169. Kallen B, Olausson PO. Maternal use of selective serotonin re-uptake inhibitors and persistent pulmonary hypertension of the newborn. Pharmacoepidemiol Drug Saf 2008;17:801-806.

170. Kieler H, Artama M, Engeland A, et al. Selective serotonin reuptake inhibitors during pregnancy and risk of persistent pulmonary hypertension in the newborn: Population based cohort study from the five Nordic countries. BMJ 2012;344:d8012.

171. Berard A, Sheehy O, Zhao JP, et al. SSRI and SNRI use during pregnancy and the risk of persistent pulmonary hypertension of the newborn. Br J Clin Pharmacol 2017; 83:1126-1133.

172. Broy P, Berard A. Gestational exposure to antidepressants and the risk of spontaneous abortion: A review. Curr Drug Deliv 2010;7:76-92.

173. Coverdale JH, McCullough LB, Chervenak FA. The ethics of randomized placebo-controlled trials of antidepressants with pregnant women: A systematic review. Obstet Gynecol 2008;112:1361-1368.

174. Gavin NI, Gaynes BN, Lohr KN, et al. Perinatal depression: A systematic review of prevalence and incidence. Obstet Gynecol 2005;106:1071-1083.

175. Wisner KL, Sit DK, Hanusa BH, et al. Major depression and antidepressant treatment: Impact on pregnancy and neonatal outcomes. Am J Psychiatry 2009;166:557-566.

176. Cohen LS, Altshuler LL, Harlow BL, et al. Relapse of major depression during pregnancy in women who maintain or discontinue antidepressant treatment. JAMA 2006;295:499-507.

177. Nulman I, Koren G, Rovet J, et al. Neurodevelopment of children following prenatal exposure to venlafaxine, selective serotonin reuptake inhibitors, or untreated maternal depression. Am J Psychiatry 2012;169:1165-1174.

178. Honein MA, Rasmussen SA, Reefhuis J, et al. Maternal smoking and environmental tobacco smoke exposure and the risk of orofacial clefts. Epidemiology 2007;18:226233.

179. Jones KL. The effects of alcohol on fetal development. Birth Defects Res C Embryo Today 2011;93:3-11.

180. Czeizel AE, Dudas I. Prevention of the first occurrence of neural-tube defects by periconceptional vitamin supplementation. N Engl J Med 1992;327:1832-1835.

181. Toohey J. Depression during pregnancy and postpartum. Clin Obstet Gynecol 2012;55:788-797.

182. Dubber S, Reck C, Muller M, et al. Postpartum bonding: The role of perinatal depression, anxiety and maternalfetal bonding during pregnancy. Arch Womens Ment Health 2015;18:187-195.

183. Dunn AL, Trivedi MH, Kampert JB, et al. Exercise treatment for depression: Efficacy and dose response. Am J Prev Med 2005;28:1-8.

184. Stuart S, Koleva H. Psychological treatments for perinatal depression. Best Pract Res Clin Obstet Gynaecol 2014;28: 61-70.

185. Stone MB, Jones L (2006). Clinical review: Relationship between antidepressant drugs and suicidality in adults. https://baumhedlundlaw.com/pdf/dolin-trial-exhibits/JX-13Clinical-Review-Relationship-Between-AntidepressantDrugs-and-Suicidality-in-Adults.pdf (last accessed June 15, 2018).

186. Miniati M, Callari A, Calugi S, et al. Interpersonal psychotherapy for postpartum depression: A systematic review. Arch Womens Ment Health 2014;17:257-268.

187. Antenatal and postnatal mental health: clinical management and service guidance NICE clinical guideline 192. www .nice.org.uk/guidance/cg45 (last accessed June 15, 2018).

188. Hill AB. The environment and disease: Association or causation? Proc R Soc Med 1965;58:295-300.

Address correspondence to:
Anick Bérard, PhD
Faculty of Pharmacy
University of Montreal
Research Center
CHU Sainte-Justine
3175 Côte-Sainte-Catherine
Montreal, Quebec, H3T 1 C5
Canada

Email: anick.berard@umontreal.ca 